\title{
Orthogonal Polarization Position Based MIMO Antenna For Wireless Applications
}

\author{
Y. V. N. R. Swamy. Banothu*1, P. Siddaiah ${ }^{2}$ \\ ${ }^{1,2}$ University College of Engineering \& Technology, Acharya Nagarjuna University Guntur, INDIA \\ Email:swamyyvnr@gmail.com
}

Received: 06th October 2017 Accepted: 14th November 2017, Published: 31st December 2017

\begin{abstract}
In this paper, we design a 4 element MIMO antenna with reduced ground plane structure to reduce the mutual coupling. Here the ground plane is reduced by etching metamaterial based concentric square shaped rings from the ground plane both in XY axis. Here initially the single antenna which is in the resemblance of $\mathrm{F}$ shape is considered and it operates at $6.94 \mathrm{GHz}$ and $9.46 \mathrm{GHz}$. The 4 element antenna is considered by placing the antenna in a orthogonal polarized positions. The frequency band we considered is in-between $6 \mathrm{GHz}$ to $10 \mathrm{GHz}$ for the analysis purpose. The dielectric material used is Rogers RT/Duroid $5880^{\mathrm{TM}}$. The comparative analysis is presented with the help of return loss curves according to the port excitation given and the MIMO antenna at each port have dual bands in the considered frequency band $6-10 \mathrm{GHz}$.
\end{abstract}

Keywords: Metamaterials (MM), F Antenna, Reduced Groud Planes (RGP), MIMO Antenna

\section{Introduction}

In recent times MIMO antennas have become very important in now a day's communication systems where multiple channels need to be dealt at the same time and the need for handling larger data and with high data rates for video streaming made it very vital to create new kind of antennas to satisfy. $\mathrm{F}$ antenna is one of the key antennas in mobile, vehicle applications [1, 2]. In the recent time the designing of antennas that are suitable of handling large band widths are considered for the $5 \mathrm{G}$ systems several countries showing interest in finding the proper frequency bands that can be utilized for $5 \mathrm{G}$ applications but the most speculated bands are $6 \mathrm{GHz}$ and above. The designing of $\mathrm{F}$ antenna above the $6 \mathrm{GHz}$ is very easy that is why it is considered most [3]. Placing the radiating elements in a compact way is very daunting task in working with the MIMO antennas. In order to avoid mutual coupling, envelope correlation etc several methods were used like placing minimum distance between the radiating elements, are having a neutral line in between the radiating elements etc, but placing the radiating elements in a orthogonal ways another way to do it.

Reducing the antenna size without affecting its performance is one of the key factors in implementing any new antennas. Etching slots from both radiating elements and the ground planes is considered to reduce the actual size of the antenna[4,5]. Now a days to reduce the overall size of the antenna and also as an alternate to the Metamaterial structures defective ground surfaces are used. Whenever there is a need to alter the feeding given to the radiating element it is usual to etch some slot on the ground below the feed. Here in the metamaterial based reduced ground planes we etch slots similar to the periodic structures in the particular area or the entire can be proved to be very useful in generating the frequency tuning or the radiation reconfiguration in our case we use it isolate the each element radiation to reduce the mutual coupling[6-8].

Due to the increase in traffic in communication systems which can process multiple gbps data to vast number of users, the demand for $5 \mathrm{G}$ is high there are few frequency bands which are being considered for the $5 \mathrm{G}$ applications in different countries. It is very important to have high bands to allow high data rate in Gbps the easy way to have high band width is when working with very high frequency bands like above $6 \mathrm{GHz}$ [9]. Though it is expected to deploy 5 generation communication systems early 2020 several researches already started exploring various secure coding methods as well as design problems and the adaptive hardware setups and it is very important to have the proper antennas which can satisfy the needs of $5 \mathrm{G}$ both in transmission and reception. So here we proposed to design antenna which can work at frequencies higher than $6 \mathrm{GHz}$.

\section{DESIGNING OF PROPOSED F ANTENNA AND THE MM BASED MIMO ANTENNA WITH RGP METAMATERIAL STRUCTURE}

\section{A. Proposed F antenna}

As the F antenna is one of the most popular antenna used for mobile communication applications we considered it for the analysis purpose here the ground plane is considered with dimensions $4.5 \times 4.5 \mathrm{~cm}$. and the dielectric substrate Rogers $\mathrm{RT} /$ Duroid $5880^{\mathrm{TM}}$ with dimensions $4.5 \mathrm{~cm} \times 4.5 \mathrm{~cm} \times 62 \mathrm{mil}$ is considered. The $\mathrm{F}$ shape is followed with strip line carrying feed from port with width $0.1 \mathrm{~cm}$ and length $1.5 \mathrm{~cm}$ short arm of $F$ with dimensions $1 \times 0.5 \mathrm{~cm}$, and $\log$ arm with $1.5 \times 0.4 \mathrm{~cm}$ and the connection between them is of $0.3 \times 0.3 \mathrm{~cm}$ dimensions the entire proposed model of $\mathrm{F}$ antenna in top view is shown in the following figure [1]. 


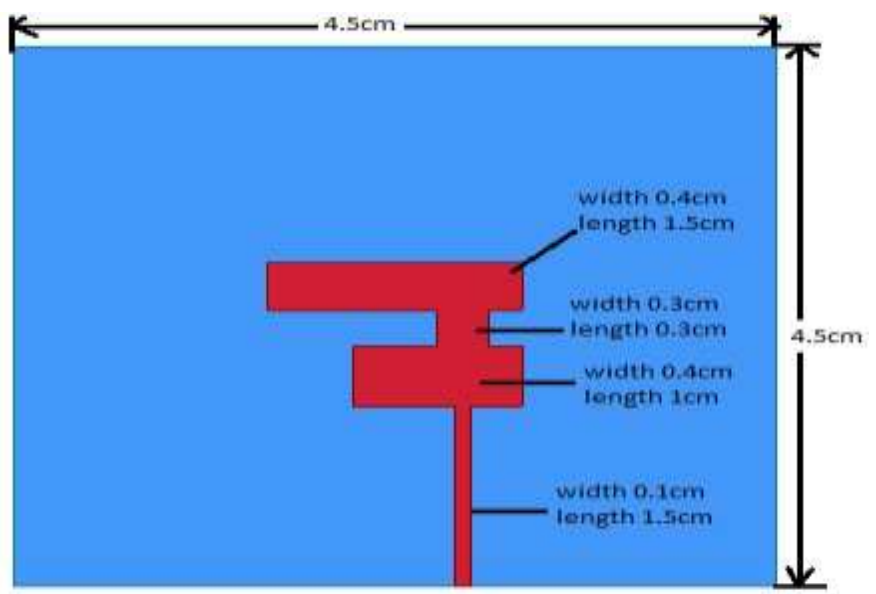

Figure [1] Top view of the proposed $\mathrm{F}$ antenna

The proposed $\mathrm{F}$ antenna return loss curve is shown in the following figure [2].

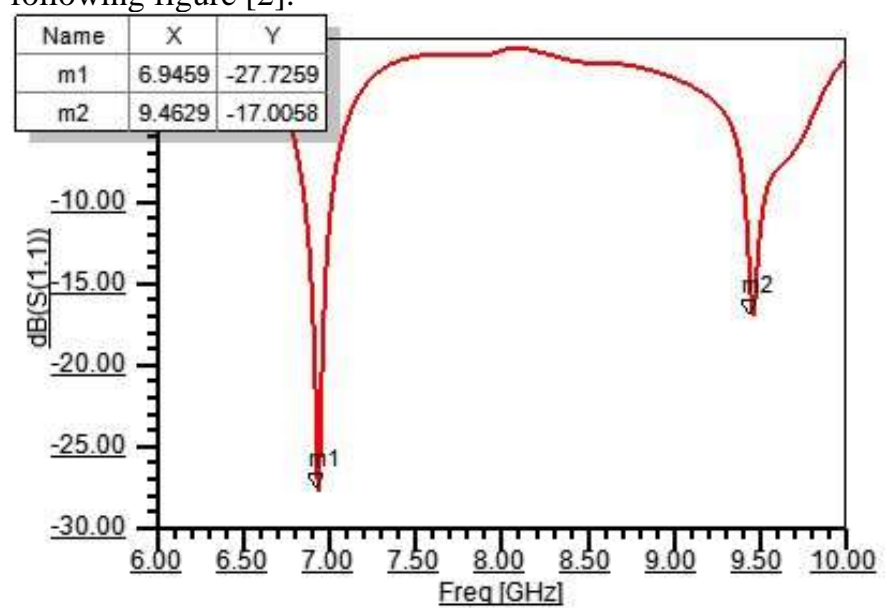

Figure [2] Return loss curve of the proposed $\mathrm{F}$ antenna The antenna works at dual band with operating frequencies at $6.94 \mathrm{GHz}$ and $9.46 \mathrm{GHz}$ with return loss $-27.7259 \mathrm{~dB}$ and $17.0058 \mathrm{~dB}$ respectively.

\section{B. Proposed MIMO antenna setup}

The $\mathrm{F}$ antenna designed above is placed in a orthogonal polarization manner as shown in the following figure [3]. Here the MIMO antenna has 4 elements in the 4 corners.

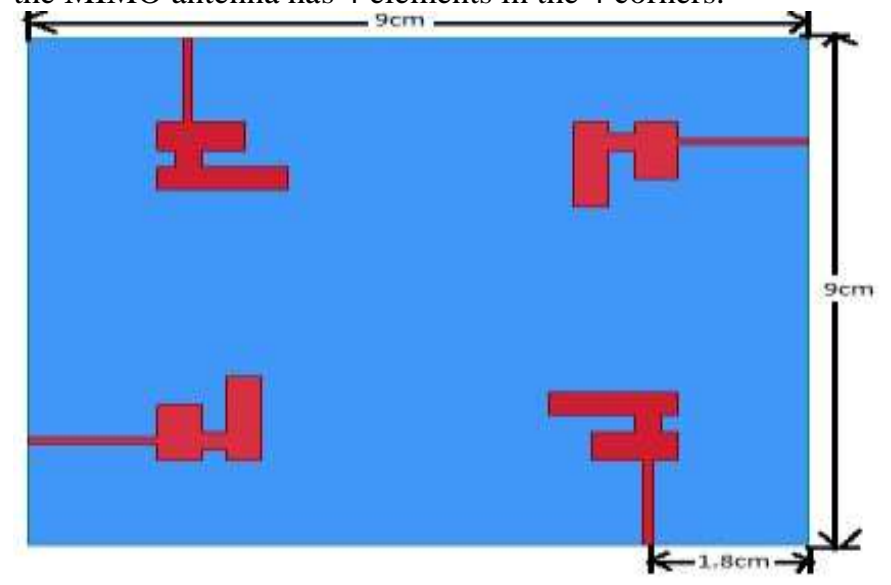

Figure [3] Top view of the proposed MIMO antenna In the above figure substrate and ground plane have dimensions $9 \times 9 \mathrm{~cm}$.

\section{Proposed 4 element MIMO antenna with MM based RGP}

The above MIMO antenna shown in the figure [3] will changed by etching the square shaped rings from the ground plane as shown in the following figure [5].

Here the MM based rings are etching like split ring resonator model from ground the square shaped ring etched from ground are $1 \mathrm{~cm}$ length and ring width of $0.4 \mathrm{~cm}$ and a square patch inside the ring with $0.4 \mathrm{~cm} \times 0.4 \mathrm{~cm}$ dimensions as shown in the figure [4].

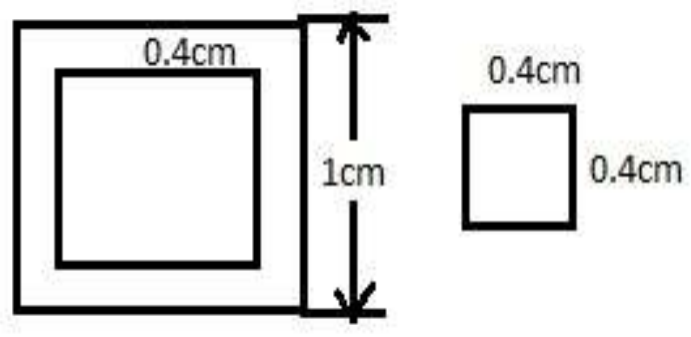

Figure [4] square ring and square patch for etching The above shown square ring and patch are etched in $\mathrm{XY}$ axis based on center of the antenna.

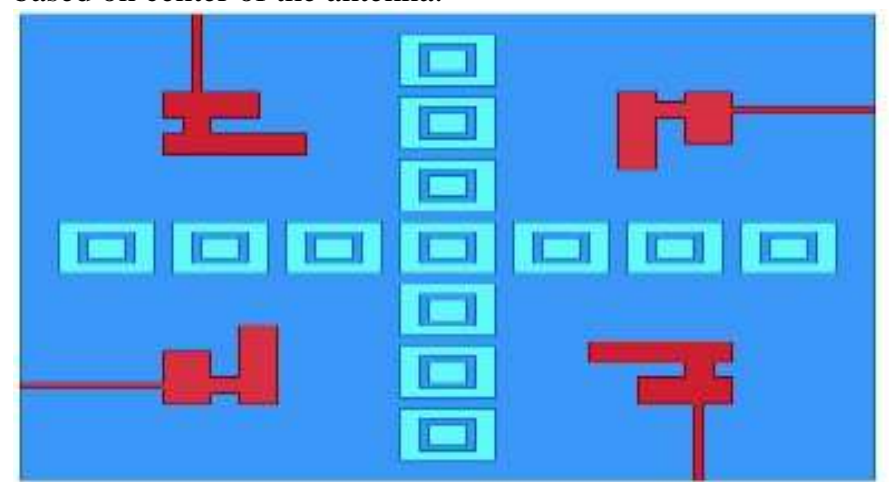

Figure [5] Proposed MIMO antenna with MM based RGP

\section{Simulated Results and Analysis}

\section{Proposed MIMO antenna}

The proposed antennas shown in figure [3] is designed and simulated and the results are presented when only port 1 is excited, when port 1 and 2 are excited, when port 1 and 3 are excited, when port1, $2 \& 3$ are excited and when all ports are excited. 
Return Loss curves

a) When only port 1 is excited

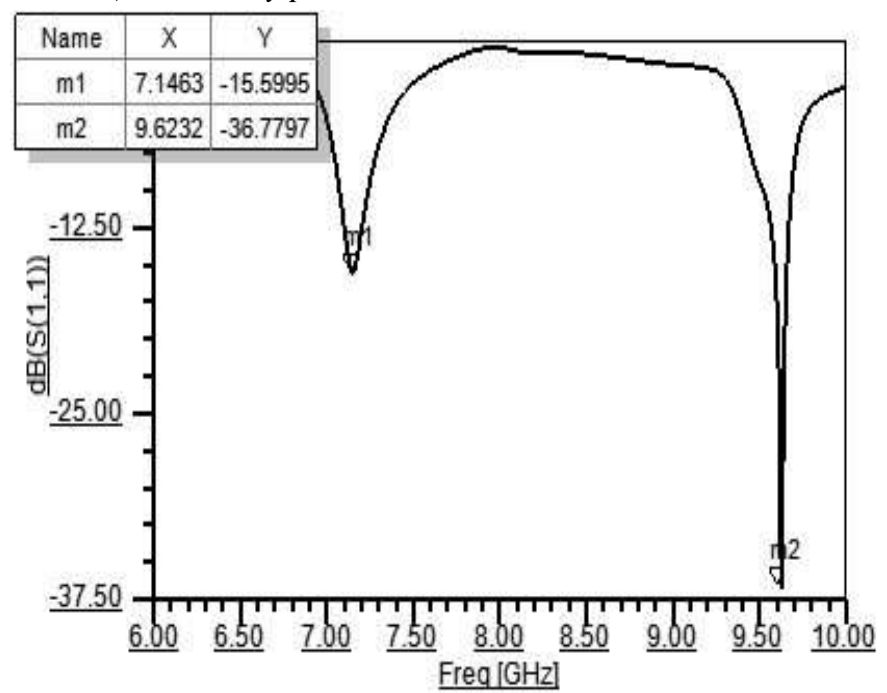

Figure [6] Return loss curve for Proposed MIMO antenna without RGP when only port 1 is excited.

Here the $S_{11}$ curve has dual band operating at 7.14 and $9.62 \mathrm{GHz}$ with return loss -15.5995 and $-36.7797 \mathrm{~dB}$ respectively.

b) When port 1 and 2 are excited

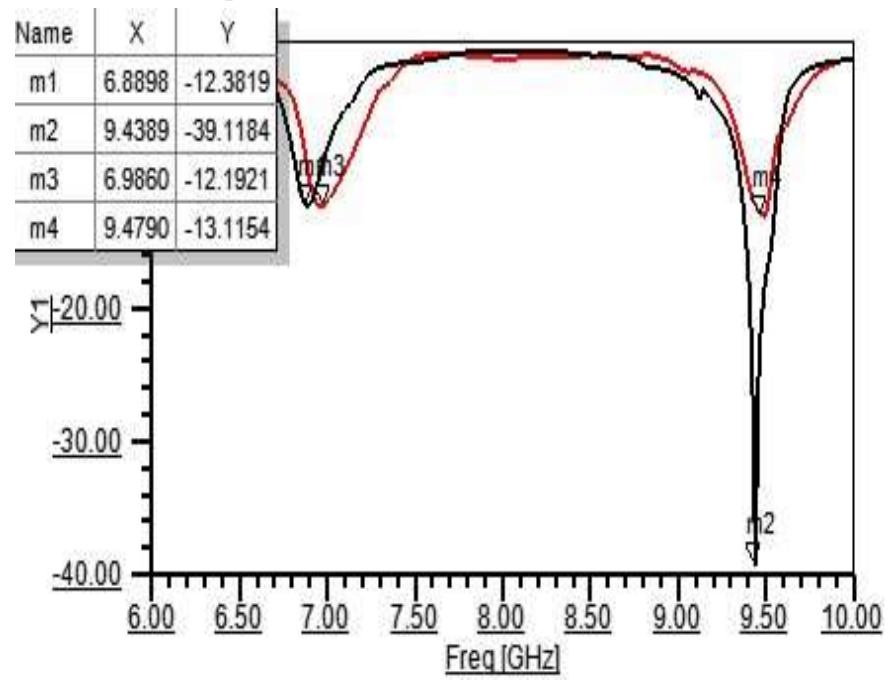

Figure [7] Return loss curve for Proposed MIMO antenna without RGP when only port 1 and 2 are excited.

In the above figure we can see that when port 1 and 2 are excited both $S_{11}$ (black line) and $S_{22}$ (red line) curves have dual bands at almost same frequency bands $\mathrm{S}_{11}$ at $6.8898 \mathrm{GHz}$, $9.4389 \mathrm{GHz}$ with return loss $-12.3819,-39.1184 \mathrm{~dB}$ and $\mathrm{S}_{22}$ at $6.986,9.479 \mathrm{GHz}$ with $-12.1921,-13.1154 \mathrm{~dB}$ respectively.

c) When port 1 and 3 are excited

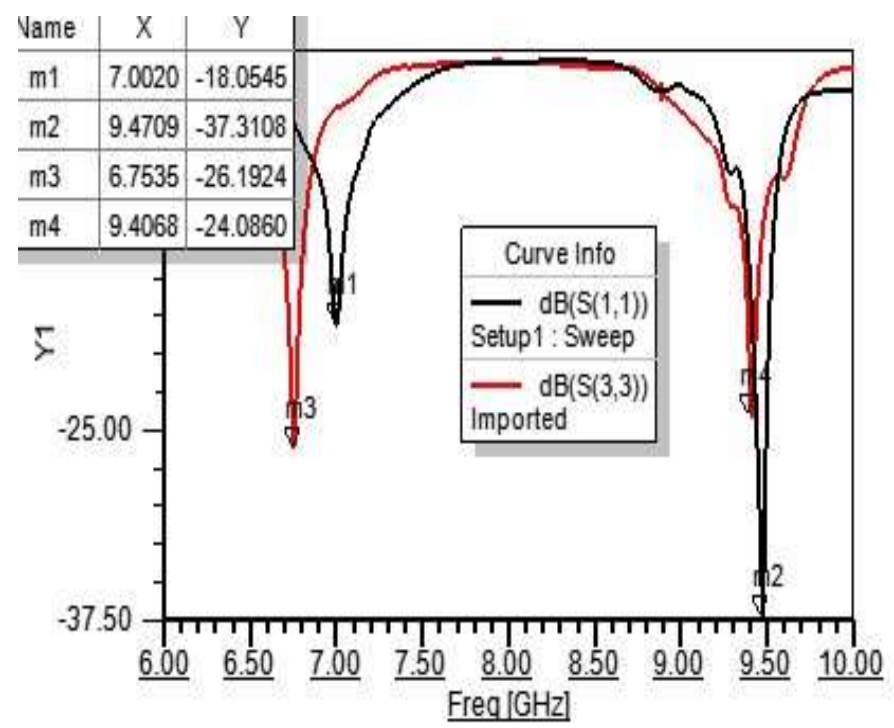

Figure [8] Return loss curve for Proposed MIMO antenna without RGP when only port 1 and 3 are excited.

In the above figure we can see that when port 1 and 3 are excited both $S_{11}$ (black line) and $S_{33}$ (red line) curves have dual bands at almost same frequency bands $S_{11}$ at $7.0020 \mathrm{GHz}$, $9.4709 \mathrm{GHz}$ with return loss $-18.0545,-37.3108 \mathrm{~dB}$ and $\mathrm{S}_{33}$ at $6.7535,9.4068 \mathrm{GHz}$ with $-26.1924,-24.0860 \mathrm{~dB}$ respectively.

d) When port 1,2, and 3 are excited

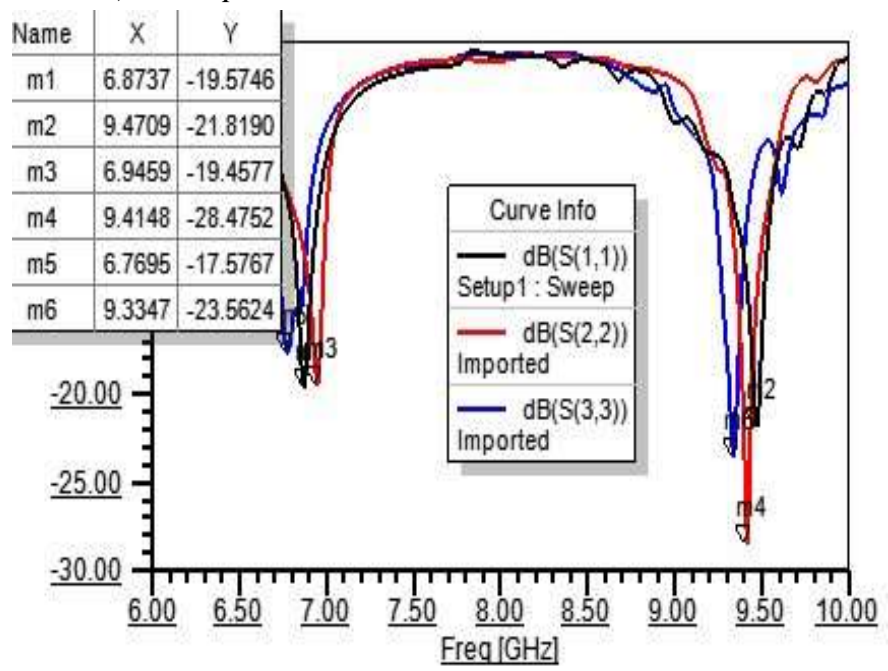

Figure [9] Return loss curve for Proposed MIMO antenna without RGP when only port 1, 2, and 3 are excited.

Similarly in the above figure [9] $S_{11}, S_{22}$ and $S_{33}$ all have dual bands. $S_{11}$ at $6.8737,9.4709 \mathrm{GHz}$ with return loss $-19.5746 \mathrm{~dB}$, $-21.819 \mathrm{~dB}, \mathrm{~S}_{22}$ at $6.9459,9.4148 \mathrm{GHz}$ with return loss $19.4577 \mathrm{~dB},-28.4752 \mathrm{~dB}$ and $\mathrm{S}_{33}$ at $6.7695,9.3347 \mathrm{GHz}$ with return loss $-17.5767 \mathrm{~dB},-23.5624 \mathrm{~dB}$ respectively. 
e) When all ports are excited

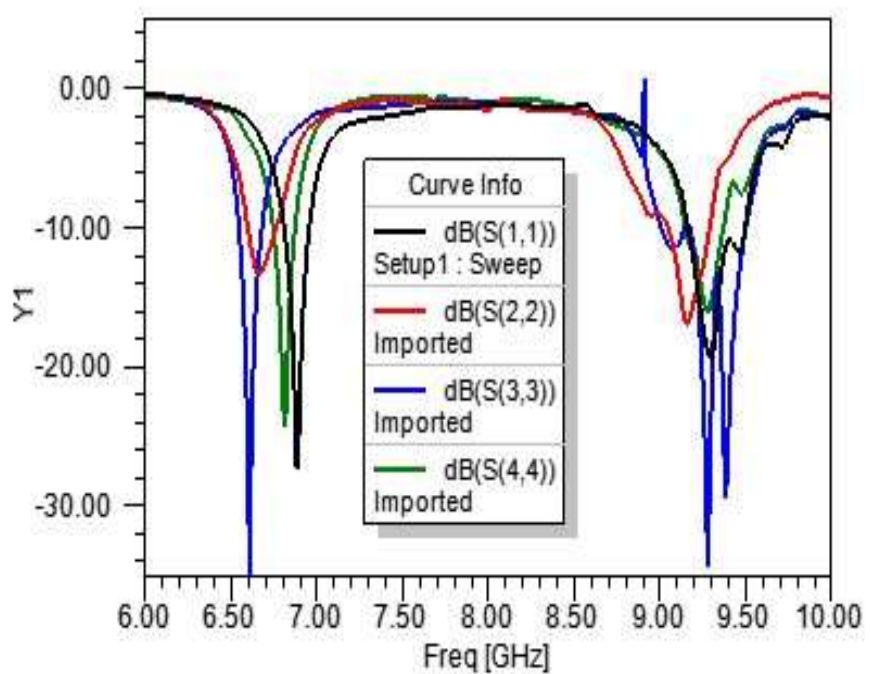

Figure [10] Return loss curve for Proposed MIMO antenna without RGP when all ports are excited.

In the above figure [10] $S_{11}$ curve operates at 6.8898 , $9.3029 \mathrm{GHz}$ with return loss $-27.2344,-19.2945 \mathrm{~dB}, \mathrm{~S}_{22}$ curve at $6.6733,9.1633 \mathrm{GHz}$ with return loss $-13.3317,-16.8193 \mathrm{~dB}$, $\mathrm{S}_{33}$ at $6.6172,9.2786 \mathrm{GHz}$ with return loss $-34.8551,-34.2440$ and $\mathrm{S}_{44}$ at $6.8176,9.2786 \mathrm{GHz}$ with return loss -24.3367 , $16.0386 \mathrm{~dB}$ respectively.

\section{E. Analysis for Proposed MIMO antenna with MM based $R G P$}

Similarly here also the results are presented as same manner from figure [6-10]. For the model setup in figure [5].

\section{a) When only port 1 is excited}

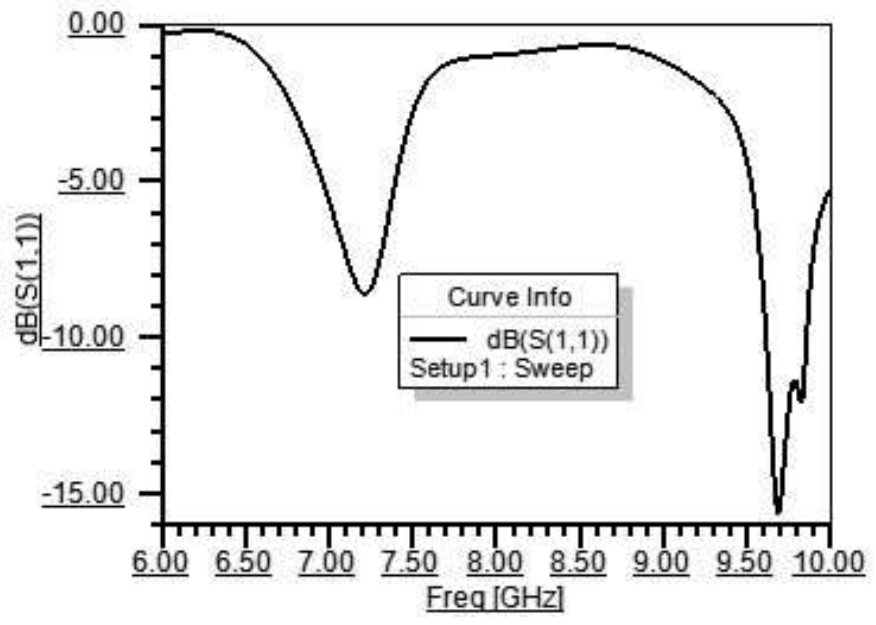

Figure [11] Return loss curve for Proposed MIMO antenna with RGP when only port 1 is excited.

Here the $S_{11}$ curve has dual band operating at 7.2024 and $9.6713 \mathrm{GHz}$ with return loss -8.5727 and $-15.5002 \mathrm{~dB}$ respectively.

b) When port 1 and 2 are excited

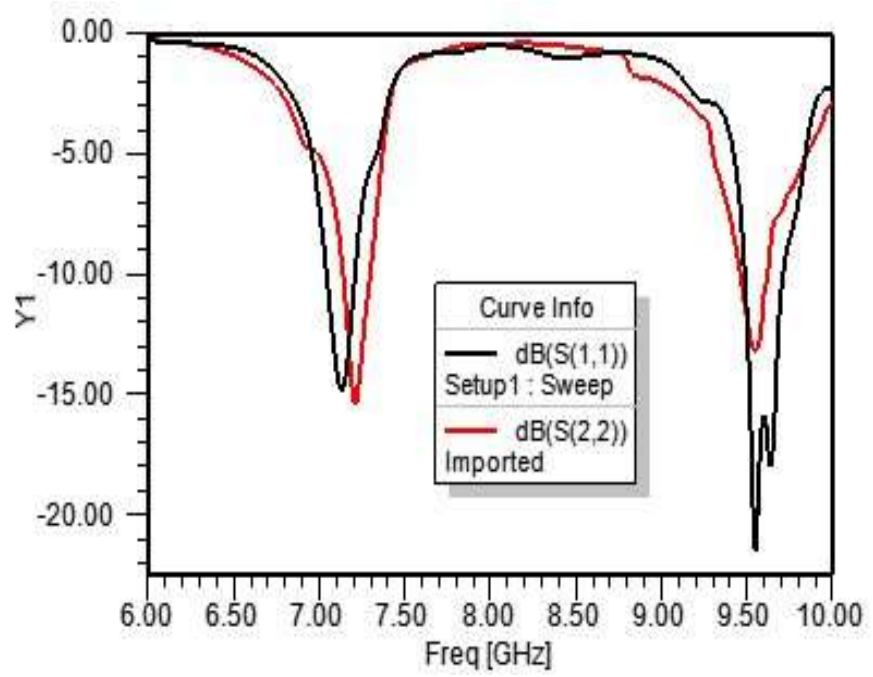

Figure [12] Return loss curve for Proposed MIMO antenna with RGP when only port 1 and 2 are excited.

In the above figure we can see that when port 1 and 2 are excited both $S_{11}$ and $S_{22}$ curves have dual bands at almost same frequency bands $S_{11}$ at $7.1383 \mathrm{GHz}, 9.5511 \mathrm{GHz}$ with return loss $-14.8190,-21.4717 \mathrm{~dB}$ and $\mathrm{S}_{22}$ at $7.2184,9.5511 \mathrm{GHz}$ with $-15.3615,-13.1725 \mathrm{~dB}$ respectively.

c) When port 1 and 3 are excited

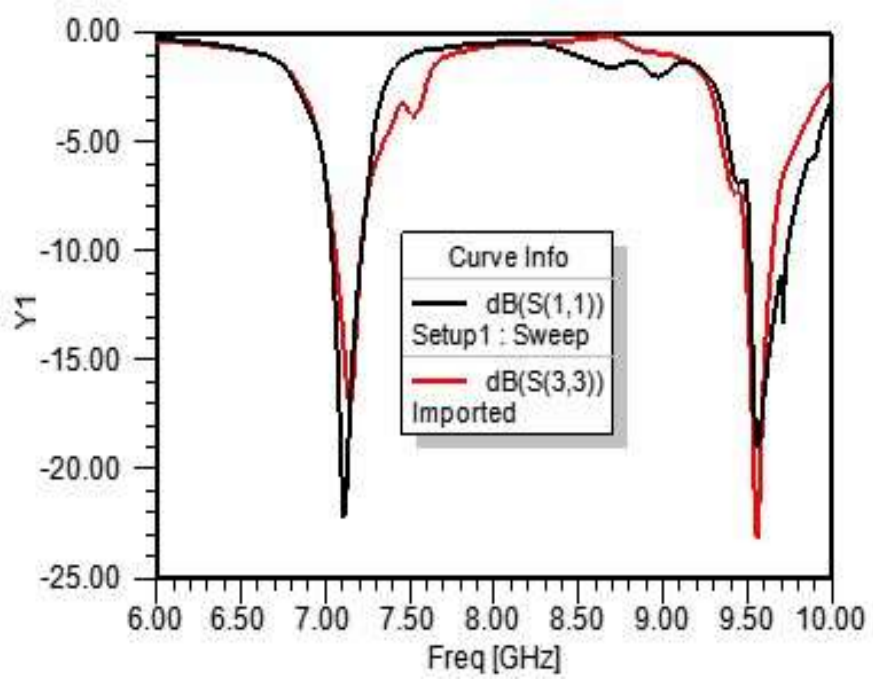

Figure [13] Return loss curve for Proposed MIMO antenna with RGP when only port 1 and 3 are excited. 
In the above figure we can see that when port 1 and 3 are excited both $S_{11}$ and $S_{33}$ curves have dual bands at almost same frequency bands $S_{11}$ at $7.1142 \mathrm{GHz}, 9.5511 \mathrm{GHz}$ with return loss $-22.1372,-19.0220 \mathrm{~dB}$ and $S_{33}$ at 7.1543, $9.5511 \mathrm{GHz}$ with $-16.9669,-23.0920 \mathrm{~dB}$ respectively.

d) When port 1,2, and 3 are excited

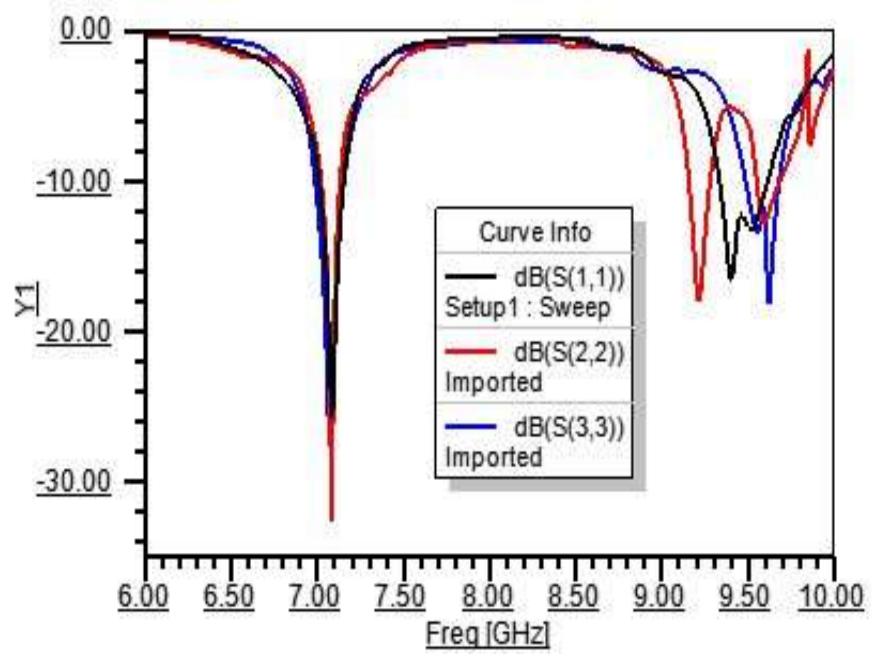

Figure [14] Return loss curve for Proposed MIMO antenna with RGP when only port 1,2 , and 3 are excited.

Similarly in the above figure [9] $\mathrm{S}_{11}, \mathrm{~S}_{22}$ and $\mathrm{S}_{33}$ all have dual bands. $S_{11}$ at $7.0902,9.4068 \mathrm{GHz}$ with return loss $-24.8144 \mathrm{~dB}$, $-16.5378 \mathrm{~dB}, \mathrm{~S}_{22}$ at $7.0902,9.2144 \mathrm{GHz}$ with return loss $32.5554 \mathrm{~dB},-17.9957 \mathrm{~dB}$ and $\mathrm{S}_{33}$ at $7.0822,9.6232 \mathrm{GHz}$ with return loss $-26.9475 \mathrm{~dB},-18.1262 \mathrm{~dB}$ respectively.

e) When all ports are excited

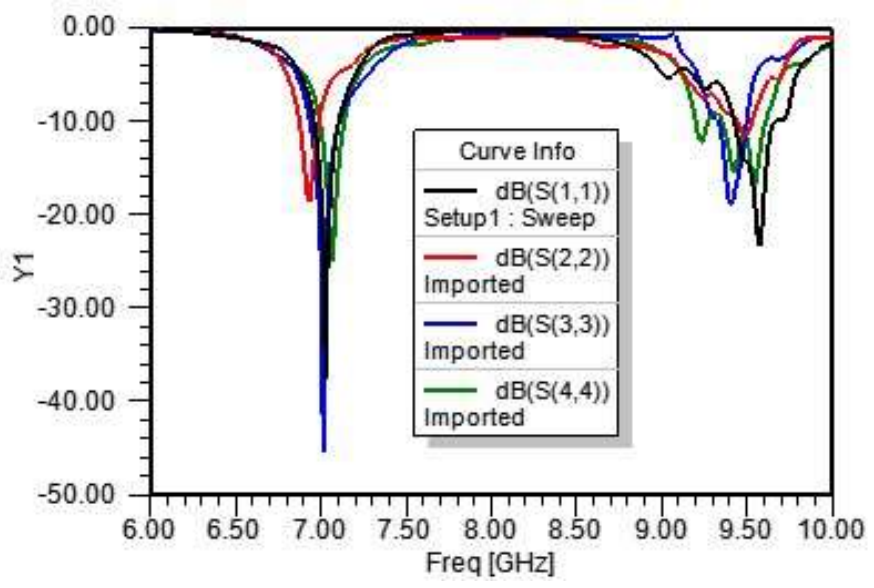

Figure [15] Return loss curve for Proposed MIMO antenna with RGP when all ports are excited.

In the above figure [10] $S_{11}$ curve operates at 7.0341, $9.5671 \mathrm{GHz}$ with return loss $-37.4557,-23.3979 \mathrm{~dB}, \mathrm{~S}_{22}$ curve at $6.9379,9.479 \mathrm{GHz}$ with return loss $-18.6278,-11.7131 \mathrm{~dB}$, $\mathrm{S}_{33}$ at $7.0180,9.3988 \mathrm{GHz}$ with return loss $-45.2838,-18.9663$ and $\mathrm{S}_{44}$ at $7.0661,9.5351 \mathrm{GHz}$ with return loss -24.9745 , $17.0642 \mathrm{~dB}$ respectively.

\section{Comparative analysis}

For the comparison purpose we consider when all ports are excited $S_{11}$ curves for proposed MIMO antenna without and with MM based RGP

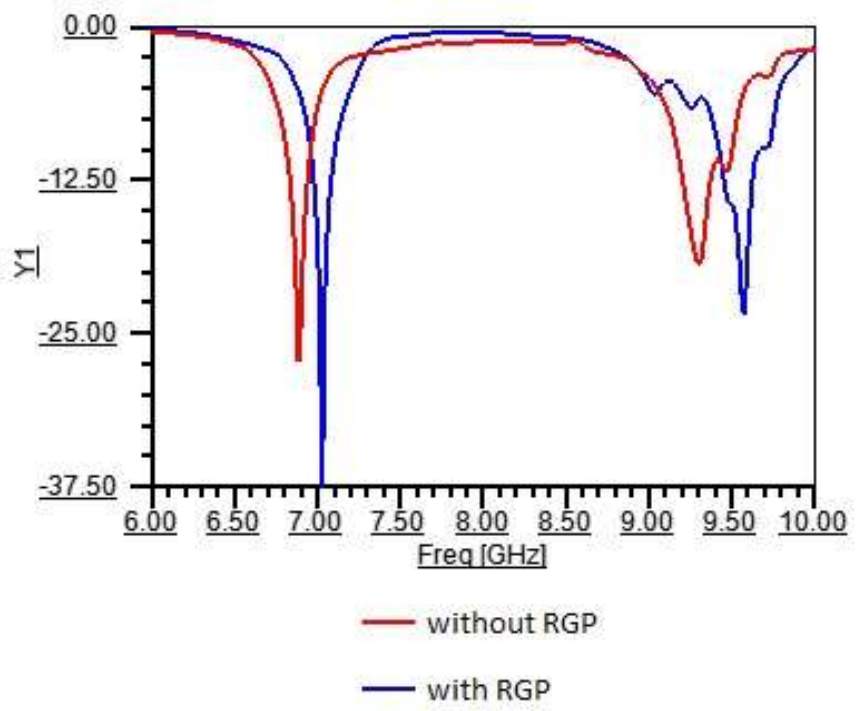

Figure [16] Comparison of $S_{11}$ when all ports are excited without RGP and with RGP.

In the above figure [16] we can clearly see that with RGP the return loss is good which means it gives better performance with RGP.

Similarly comparing $\mathrm{S}_{43}$ curves

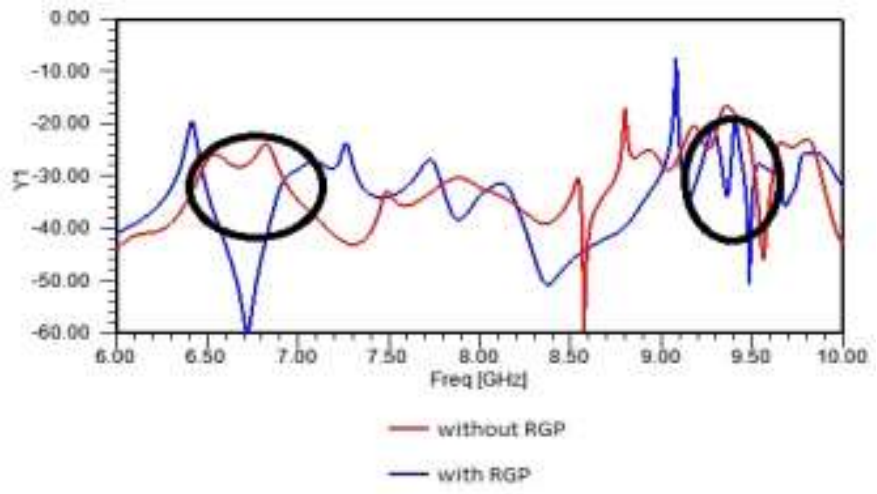

Figure [16] Comparison of $\mathrm{S}_{43}$ when all ports are excited without RGP and with RGP.

In the above figure when RGP is present mostly the S43 curve with RGP is below the S43 curve without RGP except some bands. Especially the in the working frequency bands of the designed antenna S43 curve with RGP is below the S43 curve of without RGP that means the mutual coupling reduced. 


\section{Conclusion}

The performance of proposed 4 element MIMO antenna with and without RGP is analyzed and as we can see there is slight improvement in reducing the mutual coupling by etching the ground in MIMO antenna here the proposed model without and with RGP mostly worked in frequency bands approximately around $6.5-7.2 \mathrm{GHz}$ and $9.2-9.7 \mathrm{GHz}$ with good return loss. This higher frequency band belongs to $\mathrm{c}$ and $\mathrm{x}$ bands are also being in consideration for future $5 \mathrm{G}$ wireless applications.

\section{Acknowledgement}

We would like to thank the Organization of Acharya Nagarjuna University Guntur, for support to use R\&D Laboratories.

\section{References}

[1]. Ali, M.; Guangli Yang; Huan-Sheng Hwang; Sittironnarit, T., "Design and analysis of an R-shaped dual-band planar inverted-F antenna for vehicular applications", IEEE Transactions on Vehicular Technology, vol. 53, iss. 1, pp. 29-37, January 2004.

[2]. F.N.M. Redzwan; M.T. Ali; M.N.Md Tan; N. F. Miswadi, " Design of Planar Inverted F antenna for LTE Mobile Phone Applications"; Region 10, Symposium, 2014 IEEE.

[3]. Waleed Ahmed, Asad Ali; Wasif Tanveer Khan; “ Small form Factor PIFA antenna design at $28 \mathrm{GHz}$ for $5 \mathrm{G}$ applications", Antennas and Propagation (APSURSI), 2016 IEEE International Symposium.

[4]. Raj Kumar, J. P. Shinde and M. D. Uplane" Effect of Slots in Ground Plane and Patch on Micro strip Antenna Performance", International Journal of Recent Trends in Engineering, Vol 2, No. 6, November 2009.

[5], Kai Da Xu, Yong Hong Zhang, Ronald J. Spiegel, Yong Fan, William T. Joines, and Qing Huo Liu, "Design of Stub Loaded Ring-Resonator Slot for antenna Applications", IEEE TRANSACTIONS ON ANTENNAS AND PROPAGATION, VOL. 63, NO. 2, FEBRUARY 2015.

[6]. Sara Mahmoud, W. Swelam, Mohamed Hassan, "Parametric Study of Slotted Ground Microstrip Patch Antenna" IOSR Journal of Electronics and Communication Engineering (IOSR-JECE) e-ISSN: 2278-2834,p- ISSN: 2278-8735.Volume 11, Issue 1, Ver. III (Jan. - Feb .2016), PP 01-08.

[7]. Mohammad Vatankhah Varnoosfaderani, David V. Thiel, Jun Wei Lu, "A folded slot antenna with full ground plane for wearable waterproof wireless sensors" Proceedings of IEEE APS \&URSI, 2014.

[8]. Nora Mohamed, Mohamed-Hicho; Eva Antonino Daviu; Marta Cabedo Fabres; Miguel Ferrando Bataller;
"Characteristic Modes in Slot Antennas Etched in A Finite Ground Plane", Antennas and Propagation (APSURSI), 2016 IEEE International Symposium.

[9]. Straightpath Communication Inc. "A straight Path Towards 5G(white paper)” September 16, 2015.

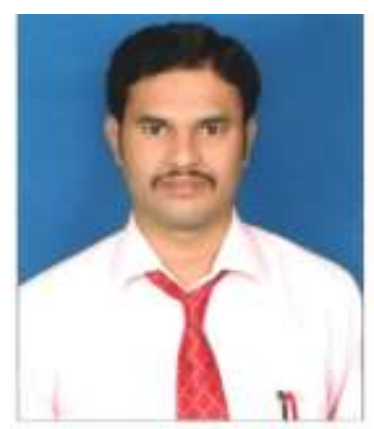

$\begin{array}{llllll}\text { B } & \mathbf{Y} & \mathbf{V} & \mathbf{N} & \mathbf{R} & \text { Swamy }\end{array}$ obtained his B.Tech degree in Electronics and communication Engineering from Acharya Nagarjuna University, Guntur, India in 2007. He received his M.Tech degree from $\mathrm{J} \mathrm{N} \mathrm{T}$ U Kakinada, Andhra Pradesh, India in 2011. He is presently pursuing Ph.D degree in Electronics and communication Engineering in the field of MIMO Antennas from Acharya Nagarjuna University, Guntur, India.He is the life member of IETE.

Dr. P Siddaiah obtained B.Tech degree in Electronics and communication Engineering from JNTUA College of engineering, Andhra Pradesh, India in 1988. He received his M.Tech degree from SV University Tirupathi, Andhra Pradesh, India. He did his Ph.D program in JNTU Hyderabad, Andhra Pradesh, India. He is the Chief Investigator for several outstanding Projects sponsored by Defence Organizations, AICTE, UGC \& ISRO. He is currently working as Professor \& PRINCIPAL,

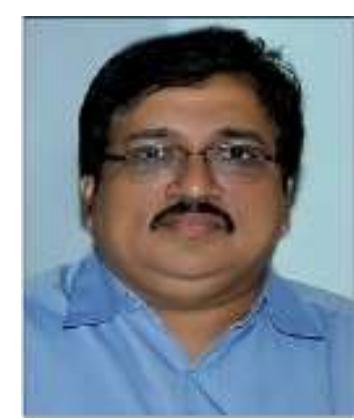
Department of ECE in University College of Engineering and Technology, Acharya Nagarjuna University, Guntur, India. He has taught a wide variety of courses for UG \& PG students and guided several projects. Several members successfully completed their Ph.D under his guidance. Several members pursuing their Ph.D degree. He has published several papers in National \& International Journals \& Conferences. He is the life member of FIETE, IE \& MISTE. 